\title{
Vibrational properties and cooperativity of the 3D spin crossover network [ $\mathrm{Fe}($ pyrazine $)]\left[\mathrm{Pt}(\mathrm{CN})_{4}\right]$
}

Received 00th January 20xx, Accepted 00th January 20xx DOI: $10.1039 / \times 0 \times x 00000 x$

\author{
Tim Hochdörffer, ${ }^{a}$ Aleksandr I. Chumakov ${ }^{b}$, Hans-Christian Willec, Volker Schünemann ${ }^{\mathrm{a}}$ and Juliusz \\ A. Wolny ${ }^{\mathrm{a}}$
}

\begin{abstract}
Nuclear inelastic scattering of synchrotron radiation has been used to determine the phonon density of vibrational states (pDOS) for the high-spin and low-spin phases of the hydrated and dehydrated isomer of the spin crossover polymer $\left[\mathrm{Fe}(\right.$ pyrazine) $]\left[\mathrm{Pt}(\mathrm{CN})_{4}\right]$. Density functional calculations have been performed for molecular models of the 3D polymeric system. The models contain $15 \mathrm{Fe}(\mathrm{II}) / \mathrm{Zn}$ (II) centres and allowed the assignment of the observed bands to the corresponding vibrational modes. Thermodynamic parameters like the mean force constant and the vibrational entropy but also sound velocities of the molecular lattices in both spin states have been derived from the pDOS. Modelling of the low-spin and highspin centres in the environment or matrix of different spin have revealed the enthalpic and entropic components of the intramolecular cooperativity. Contrary to the 1D spin crossover systems (Rackwitz et al. Phys. Chem. Chem. Phys. 2013, 15, 15450) based on the rigid 1,2,4-triazole derivatives the distortion of the low-spin iron Fe(II) centre by the matrix of high-spin $\mathrm{Fe}(\mathrm{II})$ (modelled as $\mathrm{Zn}(\mathrm{II})$ ) occurs only in two dimensions, defined by the $\left[\mathrm{M}(\mathrm{CN})_{4}\right]^{2-}$ sheets, rather than concerning all six Fe-N bonds, as in 1D systems. The enthalpic intramolecular cooperativity has been determined to $15 \mathrm{kJmol}^{-1}$ which is lower than in $1 \mathrm{D}$ systems $\left(20-30 \mathrm{kJmol}^{-1}\right)$. Yet, the entropic contribution stabilizes the low-spin state in a low-spin matrix, a behaviour which is opposite to what was found for the $1 \mathrm{D}$ systems.
\end{abstract}

\section{Introduction}

Coordination polymers with switching and memory functions are novel advanced materials with potential applications in spintronics. Among them iron containing polymers revealing a spin crossover (SCO) behaviour are considered to be a very important class. ${ }^{1}$ Depending on the type of metal ligand polymeric SCO materials can be prepared as polymers exhibiting 1D, 2D and 3D molecular networks. ${ }^{2}$ An important class of the latter are the systems involving di-, tetra-, hexa- and octacyanometallate bridging ligands. One of the most extensively studied type of the tetracyanometallate bridged one are the complexes of $[\mathrm{Fe}($ pyrazine $)]\left[\mathrm{M}(\mathrm{CN})_{4}\right](\mathrm{M}=\mathrm{Ni}, \mathrm{Pd}, \mathrm{Pt})$ type. They consist of alternate $2 \mathrm{D}$ sheets containing squareplanar units of the $\mathrm{M}(\mathrm{CN})_{4}{ }^{2-}$ anions coordinated to $\mathrm{Fe}(\mathrm{II})$ anions, with the sheets being connected through the perpendicular Fepyrazine-Fe chains.

Since the first report by Real et al. $^{3}$ on synthesis and SCO properties of $[\mathrm{Fe}($ pyrazine $)]\left[\mathrm{M}(\mathrm{CN})_{4}\right] \cdot \mathrm{nH}_{2} \mathrm{O}(\mathrm{M}=\mathrm{Ni}, \mathrm{Pd}, \mathrm{Pt}) \quad$ a plethora of studies have appeared ${ }^{1}$ reporting the two most striking properties of this class of materials, namely porosity (and hence the ability to function as Hofmann clathrates) and SCO transitions of high cooperativity. For this work two related

\footnotetext{
a. Department of Physics, Technische Universität Kaisers/autern, Erwin Schrödinger Str. 46, 67663 Kaiserslautern, Germany

b. ESRF-The European Synchrotron, CS40220 38043 Grenoble Cedex 9 France.

c. Deutsches Elektronen Synchrotron (DESY), Notkestr. 85, Hamburg, Germany

+ Electronic Supplementary Information (ESI) available: The gif files illustrating the calculated normal modes as movies. The microscope picture of the obtained sample of 1. See DOI: 10.1039/x0xx00000x
}

directions of $[\mathrm{Fe}($ pyrazine $)]\left[\mathrm{M}(\mathrm{CN})_{4}\right]$ studies are important. On the one hand Bousseksou et al. ${ }^{4}$ and later Collet et al. ${ }^{5}$ reported that single crystals of [ $\mathrm{Fe}($ pyrazine $)]\left[\mathrm{Pt}(\mathrm{CN})_{4}\right]$ can be switched between low-spin (LS) and high-spin (HS) states with a single laser pulse within the hysteresis curve. This behaviour is an example of multiplying the effect of photoexcitation behaviour, i.e. the elastically driven cooperative response of a molecular material impacted by a laser pulse. ${ }^{6}$ On the other hand, for surfactant-stabilised nanoparticles of [Fe(pyrazine)][Ni(CN) $\left.{ }_{4}\right]$ for which the reappearance of the cooperativity for ultrasmall particles was observed ${ }^{7}$ also the phonon density of vibrational states (pDOS) determined via synchrotron based nuclear inelastic scattering (NIS) was reported. ${ }^{8}$ Subsequently, Sychrotron Mössbauer Spectroscopy and Small Angle Neutron Scattering studies were performed. ${ }^{9}$ For both, LS and HS phases parameters like the sound velocity, Young's and bulk modulus and specific heat could be determined from the acoustic phonon modes. These results reveal the nature and the importance of elastic interactions for the spin transition, its spatiotemporal dynamics and the technologically relevant size dependence of cooperativity. ${ }^{10}$

Here we report the experimental pDOS as obtained from NIS experiments on the water-free and hydrated phases of the [Fe(pyrazine)] $\left[\mathrm{Pt}(\mathrm{CN})_{4}\right]$ system. In order to theoretically model the LS and the HS phases of the material we have employed density functional theory (DFT) calculations. As reliable calculations of solid state molecular vibrations of these complex systems are still hardly feasible ${ }^{11}$, calculations were performed for a finite molecular model involving 15 Fe centres. The 
obtained results allowed the assignment of the experimental bands in the pDOS to particular molecular modes. In order to quantify the intramolecular cooperative effects in this system an approach has been used which has been formerly applied for 1D SCO systems ${ }^{12}$. Finally, the vibrational entropies of the corresponding $\mathrm{Fe}^{\mathrm{LS}} \mathrm{Fe}_{14}{ }^{\mathrm{HS}}$ and $\mathrm{Fe}^{\mathrm{HS}} \mathrm{Fe}_{14}{ }^{\mathrm{LS}}$ models were calculated and derived for the LS to HS transitions. The calculations show a more pronounced entropic component of the cooperativity and a smaller enthalpic one for the 3D system under study in comparison to the 1D system reported earlier.

\section{Results and discussion}

\section{Nuclear Inelastic Scattering.}

The experimental pDOS of $[\mathrm{Fe}($ pyrazine $)]\left[\mathrm{Pt}(\mathrm{CN})_{4}\right]$ (1) and [Fe(pyrazine)] $\left[\mathrm{Pt}(\mathrm{CN})_{4}\right] \cdot 2 \mathrm{H}_{2} \mathrm{O}(2)$ are shown in Figure 1 and 2 . The temperature dependent changes of the observed pattern correspond to a typical vibrational signature of a SCO transition in $\mathrm{Fe}$ (II) complexes. The marker bands of the LS phase can be found in the $300-700 \mathrm{~cm}^{-1}$ region, while those of the HS phase are between 100 and $300 \mathrm{~cm}^{-1}$. The HS state of 1 is characterized by two bands centred at 160 and $223 \mathrm{~cm}^{-1}$, for 2 these bands are at 171 and $226 \mathrm{~cm}^{-1}$. On the other hand, in the LS state for both 1 and 2 an intensive group of bands at $320-420 \mathrm{~cm}^{-1}$ is observed, together with four groups of bands in the $420-600 \mathrm{~cm}^{-1}$ region. Additionally, both complexes show an intensive band at ca. $185 \mathrm{~cm}^{-1}$. The pDOS of 1 and $\mathbf{2}$ in both spin states are fairly similar to that observed for $50 \mathrm{~nm}$ nanoparticles of the [Fe(pyrazine)][Ni(CN $\left.)_{4}\right]$ analogue. ${ }^{8}$ Nevertheless, differences occur due to the presence of a rather strong band observed at around $\mathrm{ca}$. $480 \mathrm{~cm}^{-1}$ in the LS Ni analogue that is not seen in the pDOS of the LS phase of 1 and 2 . Also the aforementioned band at $185 \mathrm{~cm}^{-1}$ in the latter seems to be absent in $[\mathrm{Fe}($ pyrazine $)]\left[\mathrm{Ni}(\mathrm{CN})_{4}\right]$ nanoparticles. The comparison of the pDOS of $\mathbf{1}$ and $\mathbf{2}$ exhibits no significant differences for the HS phase. For the LS phase the two maxima of the band cluster between 320 and $400 \mathrm{~cm}^{-1}$ for 1 seem to merge into one for 2 . The spectral pattern between 420 and $600 \mathrm{~cm}^{-1}$ appears to be less resolved for 2 .

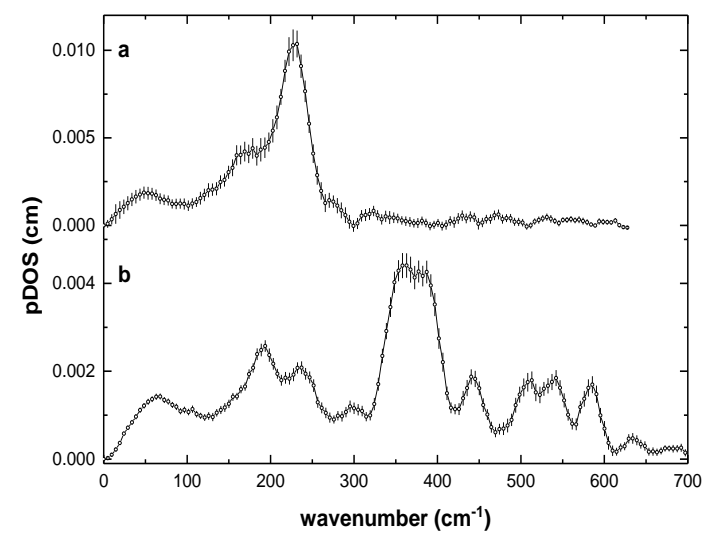

Figure 1. Experimentally obtained pDOS of 1 at $305 \mathrm{~K}$ (a) and $30 \mathrm{~K}$ (b)

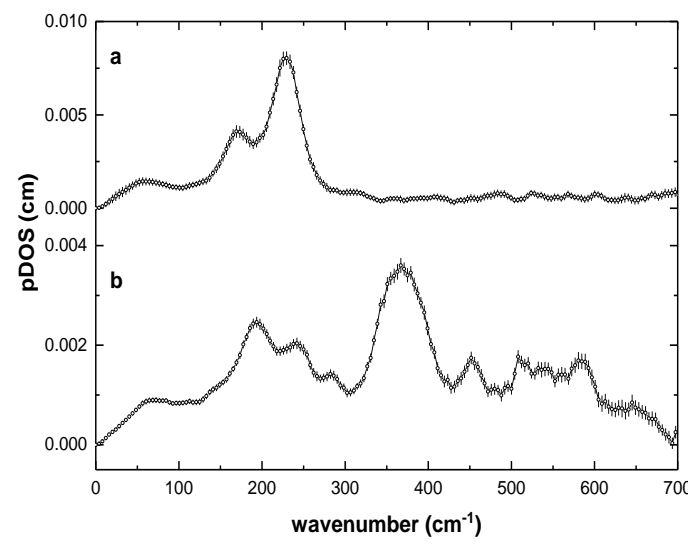

Figure 2. Experimentally obtained pDOS of 2 at $305 \mathrm{~K}$ (a) and $80 \mathrm{~K}$ (b)

The analysis of the low-energy part of pDOS allowed the derivation of the main lattice dynamical parameters (see Table 1, together with the data obtained for the nanoparticles of the $\mathrm{Ni}(\mathrm{CN})_{4}(3)$ analogue of the studied system (ref. 8)).

\begin{tabular}{|c|c|c|c|c|c|c|c|}
\hline Temperature & $\begin{array}{l}30 \mathrm{~K} \\
(1)\end{array}$ & $\begin{array}{l}80 \mathrm{~K} \\
(1)\end{array}$ & $\begin{array}{l}305 \mathrm{~K} \\
\text { (1) }\end{array}$ & $80 K(2)$ & $\begin{array}{l}305 \mathrm{~K} \\
\text { (2) }\end{array}$ & $\begin{array}{l}50 \mathrm{~K} \\
(\mathbf{3}) \\
{[\mathrm{Ref} .} \\
8]\end{array}$ & $\begin{array}{l}310 \mathrm{~K} \\
\text { (3) } \\
\text { [Ref. } \\
8]\end{array}$ \\
\hline $\begin{array}{l}\text { Norm. mean force } \\
\text { constant }\left(\mathrm{Nm}^{-1}\right)\end{array}$ & $\begin{array}{l}447.5 \\
\pm 0.1\end{array}$ & $\begin{array}{l}436.1 \\
\pm 0.1\end{array}$ & $\begin{array}{l}259.6 \\
\pm 0.1\end{array}$ & $\begin{array}{l}534.1 \\
\pm 0.1\end{array}$ & $\begin{array}{l}347.7 \\
\pm 0.1\end{array}$ & 367 & 218 \\
\hline Specific heat $\left(k_{B}\right)$ & $\begin{array}{l}0.26 \pm \\
0.02\end{array}$ & $\begin{array}{l}0.75 \pm \\
0.02\end{array}$ & $\begin{array}{l}2.46 \pm \\
0.02\end{array}$ & $\begin{array}{l}0.92 \pm \\
0.05\end{array}$ & $\begin{array}{l}2.49 \pm \\
0.03\end{array}$ & 0.51 & 2.70 \\
\hline Entropy $\left(\mathrm{k}_{\mathrm{B}}\right)$ & $\begin{array}{l}0.16 \pm \\
0.02\end{array}$ & $\begin{array}{l}0.49 \pm \\
0.01\end{array}$ & $\begin{array}{l}2.86 \pm \\
0.2\end{array}$ & $\begin{array}{l}0.57 \pm \\
0.05\end{array}$ & $\begin{array}{l}2.86 \pm \\
0.1\end{array}$ & 0.34 & 3.62 \\
\hline$f_{L M}$ & $\begin{array}{l}0.90 \pm \\
0.03\end{array}$ & $\begin{array}{l}0.85 \pm \\
0.02\end{array}$ & $\begin{array}{l}0.46 \pm \\
0.04\end{array}$ & $\begin{array}{l}0.85 \pm \\
0.02\end{array}$ & $\begin{array}{l}0.57 \pm \\
0.01\end{array}$ & 0.84 & 0.38 \\
\hline $\begin{array}{l}\text { Total vibrational } \\
\text { amplitude }(\AA)\end{array}$ & $\begin{array}{l}0.08 \pm \\
0.01\end{array}$ & $\begin{array}{l}0.10 \pm \\
0.006\end{array}$ & $\begin{array}{l}0.21 \pm \\
0.013\end{array}$ & $\begin{array}{l}0.09 \pm \\
0.005\end{array}$ & $\begin{array}{l}0.18 \pm \\
0.003\end{array}$ & 0.1 & 0.23 \\
\hline $\begin{array}{l}\text { Debye } \\
\text { temperature (K) }\end{array}$ & $\begin{array}{l}114 \pm \\
9\end{array}$ & $\begin{array}{l}113 \pm \\
8\end{array}$ & $85 \pm 6$ & $\begin{array}{l}127 \pm \\
11\end{array}$ & $\begin{array}{l}109 \pm \\
10\end{array}$ & 245 & 209 \\
\hline $\begin{array}{l}\text { Sound velocity } \\
\left(\mathrm{ms}^{-1}\right)\end{array}$ & $\begin{array}{l}2826 \pm \\
56\end{array}$ & $\begin{array}{l}2815 \pm \\
48\end{array}$ & $\begin{array}{l}2113 \pm \\
64\end{array}$ & $\begin{array}{l}3166 \pm \\
42\end{array}$ & $\begin{array}{l}2621 \pm \\
62\end{array}$ & $\begin{array}{l}2073 \\
\pm 31\end{array}$ & $\begin{array}{l}1942 \\
\pm 23\end{array}$ \\
\hline
\end{tabular}

Table 1. Main lattice dynamical parameters determined by NIS

The qualitative conclusions from the data presented in Table 1 are: i) in all three materials there is a general softening of the lattice ongoing from the LS to the HS phase, accompanied by a $10-25 \%$ decrease in sound-velocity; ii) nearly all determined parameters are the largest for $\mathbf{2}$ and the lowest for the nanoparticles of $[\mathrm{Fe}($ pyrazine $)]\left[\mathrm{Ni}(\mathrm{CN})_{4}\right]$, with that of $\mathbf{1}$ having intermediate values. Differences are only occurring for the specific heat and entropy of the LS phases. By and large, this observation points towards an increasing elasticity of the lattice in the sequence $\mathbf{2}-\mathbf{1}-\mathbf{3}^{\mathbf{8}}$. It is worth mentioning that the calorimetrically determined spin transition entropy ${ }^{13}$ is $84 \mathrm{JK}^{-1} \mathrm{~mol}^{-1}$, of which $9.4 \%$ is due to the rotational entropy of pyrazine. ${ }^{14}$ Assuming the rough estimate of the transition entropy to be different between those measured at $305 \mathrm{~K}$ and $80 \mathrm{~K}$ the values of 23,24 and $30 \mathrm{JK}^{-1} \mathrm{~mol}^{-1}$ are obtained for 1,2 and $\mathbf{3}$, respectively. This can be explained by the fact that the entropy values obtained on the basis of NIS experiments reflect only the contributions of the NIS-active vibrations. Totally symmetric stretching vibrations that do not involve movements of iron atoms are NIS inactive, nevertheless they contribute to 
the calorimetrically determined spin transition entropy. This also holds for other vibrational ligand modes which do not involve iron motion like e.g. C-H stretching and bending modes.

In fact, the calculated vibrational contribution to spin transition for the model of the title system yield the values of ca. 60 or $95 \mathrm{JK}^{-1} \mathrm{~mol}^{-1}$, depending on the environment of the switching centre (vide infra).

\section{Model system for the DFT calculations.}

In order to obtain the pDOS of the 3D network of covalent bonds of the system under study in ideal case solid-state DFT frequency calculations could be performed. However, in spite of recently reported results ${ }^{15}$ there still is no established solid DFT procedure allowing the calculations of both acoustic and optical phonons with reliable exchange-correlation functionals and basis sets. Therefore, we decided to use large model molecules of 1 in their HS and LS states. Such an approach was used to model 1D SCO systems by modelling endless chains with oligonuclear model molecules containing 5-9 Fe(II) centres. ${ }^{16,12}$ It was shown that the deliberate distribution of the HS and LS centres within a chain could be obtained when the octahedral $\mathrm{HS} \mathrm{Fe}(\mathrm{II})$ centres (Shannon-Prewitt effective radius $78 \mathrm{ppm}$ ) are replaced with $\mathrm{Zn}$ (II) (Shannon-Prewitt effective radius 74 ppm) in the starting geometry for optimisation. In this way the computationally demanding calculations with very high multiplicities could be avoided. This similarity of ionic radii leads often to the isostructurality of the $\mathrm{HS} \mathrm{Fe}$ (II) and $\mathrm{Zn}$ (II) molecules hence the dilution of the $\mathrm{Fe}$ (II) SCO complexes in the matrix of $\mathrm{Zn}$ (II) analogues is commonly used in the studies of cooperativity of spin transition in the Fe(II) complexes. ${ }^{17,18}$ As a rule such a dilution leads to a much more gradual spin transition. For the class of the 3D complexes under study such effects have been also observed. ${ }^{13,19}$

The choice of the appropriate model is necessarily a compromise: it has to be large enough to include all structural features relevant for the vibrational pattern and small enough to allow the feasibility of the computations. We found that the replacement of the $\mathrm{Pt}$ atoms with $\mathrm{Pd}$ in the model structure $\left.\left\{\mathrm{Fe}_{15} \text { (pyrazine }\right)_{20}\left[\mathrm{Pd}(\mathrm{CN})_{4}\right]_{12}\left(\mathrm{CH}_{3} \mathrm{CN}\right)_{24}\right\}^{6+}$ depicted in Figure 3 provides a reasonable model for the LS phase. The $\mathrm{pdb}$ files of the optimised structures corresponding to the LS and HS phases are given in the ESI. The model has an initial $D_{4 h}$ symmetry with the $\mathrm{Fe}(1)$ site occupying the inversion centre. The HS phase was calculated with a model structure in which $\mathrm{Fe}(\mathrm{II})$ was replaced with Zn(II).

At this point it has to be emphasized that we do not attempt to predict neither the transition temperature nor the observed type of transition for the system under study. It is clear that solely the substitution of Pd to Pt in the class of complexes under study brings about a change of transition temperature as well as a change in the shape of the hysteresis. ${ }^{3}$ On the other hand, although the crystal structure of $[\mathrm{Zn}($ pyrazine $)]\left[\mathrm{Pt}(\mathrm{CN})_{4}\right]$ is not known, the available data for $1^{4 \mathrm{~b}}$ and [Ni(pyrazine)] $\left[\mathrm{Ni}(\mathrm{CN})_{4}\right]^{20}$ exhibit that the replacement of both metal centres with another cation may lead to a change in crystal space group ( $\mathrm{P} 4 / \mathrm{mmm}$ and $\mathrm{P} 4 / \mathrm{m}$, respectively) and cell size with the same overall molecular structure. Thus, the modelling of the molecules under study with use of Pd instead of Pt and $\mathrm{Zn}$ instead of high-spin $\mathrm{Fe}$ (II) (together with acetonitrile molecules used to model the $\mathrm{N}$-bonds to $\mathrm{Fe}$ (II) for some centres) may be an additional reason for the observed discrepancy between experimentally observed and calculated pDOS. Furthermore, the accuracy of the applied DFT methods as well as the finite size of the model molecule may account for differences in simulations and experiment.

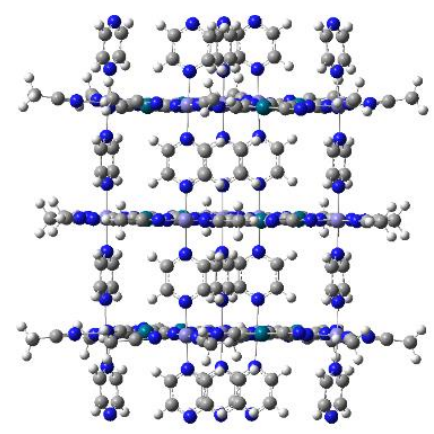

Figure 3. Perspective view of 1.

The shape of the model represents a cuboid based on a FePd grid. It is the atom $\mathrm{Fe}(1)$ in the approximate inversion centre that has the closest environment to that observed in the crystal structure. The two other Fe(II) centres lying in the pyz-Fe-pyz$\mathrm{Fe}(1)$-pyz-Fe-pyz chain are similar in this respect, the only difference being that one of the pyrazines coordinated to each is monocoordinating. The remaining $12 \mathrm{Fe}$ (II) centres lie on the longer edges of the cuboid defined by four pyz-Fe-pyz-Fe-pyzFe-pyz linkages and fall into two types: eight occupy the corners of the cuboid and four lie in the middle of the edges. All are modelled with two $\mathrm{NC}^{-}$anions replaced by acetonitriles. The reason for this is the electrostatic effect of the anions. For the alternative $\left.\left\{\left[\mathrm{Fe}_{15} \text { (pyrazine }\right)_{20}\right]\left[\mathrm{Pd}(\mathrm{CN})_{4}\right]_{12}(\mathrm{NC})_{24}\right\}^{18-}$ model the high negative charge led to the distortion of the cuboidal shape, including the tetrahedral distortions of the $\mathrm{Pd}(\mathrm{CN})_{4}{ }^{2-}$ anions when optimized with DFT. The LS Fe(II) and Zn(II) models were optimised for a $S_{4}$ symmetry point group. As may be seen in Figure 3 the higher symmetry is lifted due to non-coplanar alignment of the $\mathrm{MeCN}$ and $\mathrm{CN}^{-}$ligands protruding from four faces of the cuboid. This effect of geometry optimisation is, in our opinion, related to the electrostatic repulsion and is unavoidable within the applied model.

The principal calculated and experimental ${ }^{21}$ bond distances are shown in Table 2. The calculated metal-ligand bond lengths are in reasonable agreement with the experimentally obtained ones, the largest difference, i.e. that between calculated $\mathrm{Zn}$ $\mathrm{N}(\mathrm{C})$ and HS-Fe-N(C) determined by X-ray diffraction being less than $0.09 \AA$ A. Generally, the applied model yields shorter Fe-N bonds than those observed experimentally. Another structural parameter important for the thermodynamics of the spin transition in the class of complexes under investigation is the mutual tilt of the pyrazine ring in the pyz-Fe-pyz-Fe-pyz chains. ${ }^{22}$ While the X-ray data ${ }^{21}$ reveals the rotational disorder of the pyrazine ring, the theoretical modelling 22 predicts the 
dependence of the energy on the tilt between pyrazine plane and the $\mathrm{Fe}-\mathrm{N}(\mathrm{C})$ bonds with the minimal energy corresponding to staggered orientation of pyrazine plane and Fe-N(C) bonds. Indeed, in our model the corresponding dihedral angles are between 39 and 51 degrees, i.e. the aromatic ring plane nearly exactly bisects the $\mathrm{N}(\mathrm{CN})-\mathrm{Fe}-\mathrm{N}(\mathrm{CN})$ angles for cis coordinated nitrogen atoms. The mutual orientation of the pyrazine ring in the Fe-pyrazine chains is different for the "central" $S_{4}$ axis involving the atom in the inversion centre and for the four "edge" axis. For the former, both for LS and HS (Zn) phases, the four rings are alternately rotated at $45^{\circ}$ in line with the $S_{4}$ symmetry. For the latter they are all parallel.

Table 2. Calculated and experimental ${ }^{15}$ bond lengths for 1 . The calculated Pt-CN distances correspond to the Pd-CN distances as used in the model molecule.

\begin{tabular}{|c|c|c|c|c|}
\hline \multicolumn{5}{|c|}{ Distances $(\AA)$} \\
\hline & $\mathrm{Fe}-\mathrm{N}(\mathrm{pyz})$ & Fe-NC & Fe-pyz-Fe & Pt-CN \\
\hline X-ray LS & 2.068 & 2.011 & 6.490 & 1.949 \\
\hline LS & 2.013 & 1.956 & 6.855 & 2.012 \\
\hline X-ray HS & 2.255 & 2.189 & 7.322 & 1.997 \\
\hline $\mathrm{Zn}$ & 2.169 & 2.139 & 7.177 & 2.019 \\
\hline
\end{tabular}

\section{DFT calculated normal modes and pDOS.}

The experimental and calculated ${ }^{57} \mathrm{Fe}$ pDOS are shown in Figures 4 and 5, for the LS and HS state respectively. The best fit between calculated and experimental pDOS are obtained when all 15 iron atoms are taken into account in the calculations of the pDOS. The obtained patterns (s. Fig. $4 b$ and $5 b$ ) reproduce the experimental pDOS fairly well which allows the assignment of the experimental bands to the DFT calculated ones.

\section{Low-spin phase.}

As stated before four groups of bands are observed in the 420$600 \mathrm{~cm}^{-1}$ region for 1 (see Figure 1 and 4a). The first centred at $580 \mathrm{~cm}^{-1}$ may be assigned to the asymmetric band due to vibrations in the $550-580 \mathrm{~cm}^{-1}$ region, in which the two at 554 and $567 \mathrm{~cm}^{-1}$ involve the non-zero amplitude of $\mathrm{Fe}(1)$. At least five NIS-active (non-zero amplitude of iron) $E$ modes are predicted in this region. Four of them at 552, 554, 556 and $561 \mathrm{~cm}^{-1}$ involve the $\mathrm{Fe}-\mathrm{N}(\mathrm{C})$ stretching, coupled to $\mathrm{Pd}-\mathrm{C}$ stretching. Additionally, a slight bending of the pyrazine ring occurs. This bending becomes very strong for the next $E$ vibration predicted at $569 \mathrm{~cm}^{-1}$. The movies showing the vibrations are included in Supplementary Materials. The next experimentally observed band occurs at ca. $540 \mathrm{~cm}^{-1}$. In this region the DFT calculations predict the $\mathrm{E}$ mode at $545 \mathrm{~cm}^{-1}$. This mode combines again the $\mathrm{Fe}-\mathrm{N}(\mathrm{C})$ stretching and pyrazine bending, leading to an effective $\mathrm{N}(\mathrm{pyz})-\mathrm{Fe}-\mathrm{N}(\mathrm{C})$ bending. Additionally, the Fe-N(C)/Pd-C stretching is predicted at 522, $537,539,541$ and $542 \mathrm{~cm}^{-1}$. The last band observed in the experiment over $500 \mathrm{~cm}^{-1}$ is the sharp asymmetric band at $502 \mathrm{~cm}^{-1}$. The DFT calculations predict a double structure at 493 and $500 \mathrm{~cm}^{-1}$. Apart from few bands over $500 \mathrm{~cm}^{-1}$ of Fe-N(C) stretching type, a few modes are predicted between 491 and $497 \mathrm{~cm}^{-1}$. In this case the stretching is not due to movement of the cyanide along the Pd-Fe axis. Rather, the $\mathrm{CN}^{-}$ligands swing in the planes perpendicular to the $\mathrm{Fe}(\mathrm{NC})_{4}$ plane resulting in a mixture of stretching and bending (see the movie Is_E492.gif). The next feature of the experimentally derived pDOS is a group of bands between ca. 425 and $460 \mathrm{~cm}^{-1}$, with two bands at 430 and $440 \mathrm{~cm}^{-1}$ resolved at $30 \mathrm{~K}$. The DFT simulation reveals a weak band at ca. $456 \mathrm{~cm}^{-1}$ due to few modes similar to those in the $491-497 \mathrm{~cm}^{-1}$ region. In the $320-420 \mathrm{~cm}^{-1}$ region a cluster of intensive bands is observed. The DFT simulated pDOS is consistent with the experiment, exhibiting a similar cluster in the ca. $320-410 \mathrm{~cm}^{-1}$ area. While the vibrations predicted over $400 \mathrm{~cm}^{-1}$ correspond to the modes involving both stretching and bending of $\mathrm{Fe}-\mathrm{N}(\mathrm{C})$ and (with smaller amplitude) Pd-C bonds, the bands at ca. $395 \mathrm{~cm}^{-1}$ corresponds to high-amplitude $\mathrm{Fe}$ $\mathrm{N}$ (pyz) stretching coupled to the Fe/Pd-N/C bending due to $\mathrm{CN}$ flipping. The next band in the simulated pDOS at $384 \mathrm{~cm}^{-1}$ is due to Fe-N(C) stretching coupled to Fe-N(pyz) bending. The next maxima in the experimentally detected cluster are observed at 363 and $353 \mathrm{~cm}^{-1}$. The first may be related to the predicted $\mathrm{E}$ vibrations at $365 \mathrm{~cm}^{-1}$ involving the correlated $\mathrm{Fe}-\mathrm{N}(\mathrm{C})$ stretching in all $\left\{\mathrm{Pd}\left[(\mathrm{CN})_{4}\right]^{2-}\right\}$ planes. The second one may correspond to the Fe-N(pyz) stretching predicted at $353 \mathrm{~cm}^{-1}$.

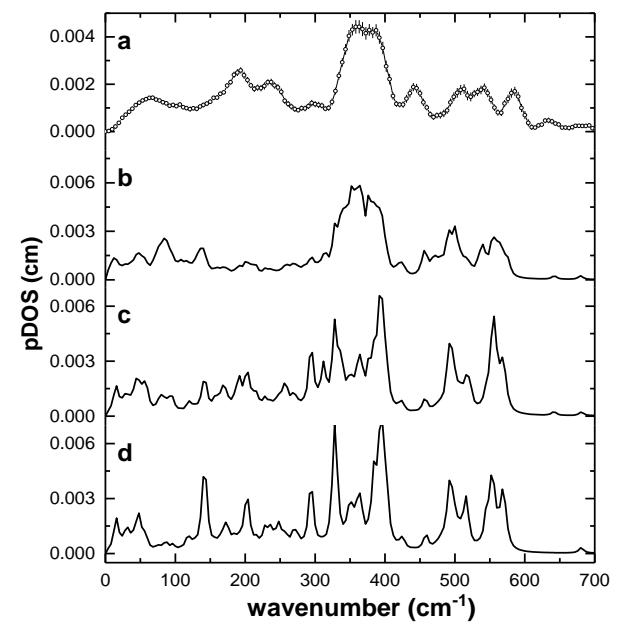

Figure 4. Comparison of the experimental and DFT calculated (CAMB3LYP/CEP-31g) pDOS for the LS state of 1. a Experimentally obtained pDOS of 1 taken at $T=30 \mathrm{~K}$. pDOS calculated $\mathbf{b}$ for vibrations involving all iron atoms, c for three irons lying on the $S_{4}$ axis and $\mathbf{d}$ for the central Fe(1) are shown.

The lower-energy shoulder of the discussed experimental band may be interpreted as the $\mathrm{Fe}-\mathrm{N}(\mathrm{pyz})$ stretching predicted at $329 \mathrm{~cm}^{-1}$ ( $B$, two vibrations), Fe- $\mathrm{N}_{6}$ stretching and bending at $338 \mathrm{~cm}^{-1}$ and $327 \mathrm{~cm}^{-1}$. The weak band in the experimental pDOS observed at ca. $300 \mathrm{~cm}^{-1}$ could originate from predominantly $\mathrm{Fe}-\mathrm{N}$ (pyz) bending modes, coupled to a weak stretching and bending of $\mathrm{Fe}-\mathrm{N}(\mathrm{C})$, predicted as E vibrations at 293 and $298 \mathrm{~cm}^{-1}$. The next two experimentally observed vibrations are seen at ca. 228 and $243 \mathrm{~cm}^{-1}$. The vibrational amplitude of iron in these modes is rather small and it is rather difficult to assign them to the calculated modes. At least two $E$ modes are predicted at 255 and $247 \mathrm{~cm}^{-1}$ comprising the bending of $\mathrm{FeN}_{6}$ bonds with some admixture of stretching, that involve the significant amplitude of iron atoms. Finally, three 
intensive bands are observed at 193, 184 and $164 \mathrm{~cm}^{-1}$. The corresponding intensity of the simulated pDOS occurs at ca. $140 \mathrm{~cm}^{-1}$ and involves the modes corresponding to movement of the $\mathrm{FeN}_{6}$ core as a whole along the pyz-Fe-pyz axis. In the lowenergy area there are three sharp bands at 116, 107, $97 \mathrm{~cm}^{-1}$ and a broader one at $\mathrm{ca} .73 \mathrm{~cm}^{-1}$. The DFT simulations predicts in this area $\mathrm{E}$ vibrations, involving the $\mathrm{Fe}-\mathrm{N}$ bending, being a part of flipping of the ligands as whole at 127, 122, 120, 118 and $108 \mathrm{~cm}^{-1}$. A similar fully symmetric vibration is predicted at 111 and $107 \mathrm{~cm}^{-1}$. Two E vibrations of significant Fe amplitude are predicted at 96 and $97 \mathrm{~cm}^{-1}$, involving the high-amplitude vibration of the pyrazine ring (hampered rotation along the $\mathrm{N}$ $\mathrm{N}$ axis). A different mode of pyrazine movement is predicted at 90 and $87 \mathrm{~cm}^{-1}$. Here the aromatic ring shifts along the $\left[\mathrm{Pd}(\mathrm{CN})_{4}\right]^{2-}$ anions sheet. A number of vibrations of different symmetries that involve the ligands flipping are predicted at ca. $75 \mathrm{~cm}^{-1}$. The $\mathrm{E}$ vibration at $57 \mathrm{~cm}^{-1}$ with a significant amplitude of $\mathrm{Fe}(1)$ is similar to the modes predicted in the $108-127 \mathrm{~cm}^{-1}$ area.

\section{High-spin phase.}

The vibrations for the HS phase of $\mathbf{1}$ were modelled by the calculations for the $\left.\left\{\left[\mathrm{Zn}_{15} \text { (pyrazine }\right)_{20}\right]\left[\mathrm{Pd}(\mathrm{CN})_{4}\right]_{12}\left(\mathrm{CH}_{3} \mathrm{CN}\right)_{24}\right\}^{6+}$ cation. The iron pDOS was then calculated assuming that the vibrations of the iron system occur at the same frequencies as for the $\mathrm{Zn}(\mathrm{II})$ model.

As stated above the experimental pDOS reveals a broader asymmetric band at ca. $223 \mathrm{~cm}^{-1}$ and a group of three sharp bands at ca. $150-170 \mathrm{~cm}^{-1}\left(150,159\right.$ and $169 \mathrm{~cm}^{-1}$ ) (see Fig. 5a). The DFT calculations reveal that the first cluster is a superposition of several bands. Firstly, there are two $\mathrm{E}$ modes predicted at 243 and $242 \mathrm{~cm}^{-1}$ that involve the weak $\mathrm{Fe}-\mathrm{N}(\mathrm{C})$ stretching coupled to Fe-N(pyz) bending. Additionally, the E vibration at $241 \mathrm{~cm}^{-1}$ and the two A vibrations at $240 \mathrm{~cm}^{-1}$ are predicted, involving the $\mathrm{Fe}-\mathrm{N}(\mathrm{C})$ stretching and bending. The E vibration at $239 \mathrm{~cm}^{-1}$ involves also the Fe-N(pyz) bending due to swinging of the pyrazines in the plane perpendicular to the $\left[\mathrm{Pd}(\mathrm{CN})_{4}\right]^{2-}$ sheets, similar to the band at $233 \mathrm{~cm}^{-1}$. Finally, the B vibration at $237 \mathrm{~cm}^{-1}$ corresponds to bending of the Fe-N-C-Pd linkage with the high-amplitude movement of cyanides in the Fe-pyz-Fe direction, i.e. Fe-N(C) bending couple with Fe-N(pyz) stretching. A more intense band in the pDOS is predicted at ca. $215 \mathrm{~cm}^{-1}$. It may be ascribed to several vibrations. The one at $223 \mathrm{~cm}^{-1}$ is a high-amplitude Fe-N(pyz) stretching of $\mathrm{Fe}(1)$. The $\mathrm{E}$ vibration at $221 \mathrm{~cm}^{-1}$ is related to bending and stretching of all Fe-N bonds, with pyrazines involved either in stretching or bending coupled to the above mentioned swinging. Of two bands at $219 \mathrm{~cm}^{-1}$ one is due to a mode similar to that at $223 \mathrm{~cm}^{-1}$ while the second one resembles that at $221 \mathrm{~cm}^{-1}$. The maximum of the calculated pDOS for this band appears at ca. $212 \mathrm{~cm}^{-1}$ and corresponds to three modes, the fully symmetric ones at $212 \mathrm{~cm}^{-1}$ and $211 \mathrm{~cm}^{-1}$ and an E mode at $211 \mathrm{~cm}^{-1}$. They are of similar type as the ones discussed above (see movies in ESI), with the symmetric band at $211 \mathrm{~cm}^{-1}$ showing a predominantly Fe-N(pyz) stretching character. Similar bands are also predicted at $208-209 \mathrm{~cm}^{-1}$. The second group of vibrations that may be assigned to the low-energy tail of the experimental band at $223 \mathrm{~cm}^{-1}$ are predicted with a maximum at ca. $192 \mathrm{~cm}^{-1}$. The modes in this region show some admixture of bending to the stretching character, which is even more pronounced for the E vibrations at $181 \mathrm{~cm}^{-1}$ (see movies in ESI). The three observed bands in the $150-170 \mathrm{~cm}^{-1}$ region may be assigned to two groups of vibrations predicted at ca. 137 and $156 \mathrm{~cm}^{-1}$. The latter may be assigned to the A modes at 158 and $155 \mathrm{~cm}^{-1}$ revealing the Fe-N(pyz) stretching and Fe-N $(C)$ bending. Furthermore the $\mathrm{E}$ vibration at $144 \mathrm{~cm}^{-1}$ is predicted, displaying the Fe-N bending with some Fe- $\mathrm{N}(\mathrm{C})$ stretching. Finally, two NIS-active E vibrations are predicted at 138 and $139 \mathrm{~cm}^{-1}$. The low energy vibration is observed experimentally at ca. $83 \mathrm{~cm}^{-1}$. The DFT simulation predicts three NIS-active vibrations in this area. The $\mathrm{B}$ vibration with a high amplitude of $\mathrm{Fe}(1)$ is predicted at $105 \mathrm{~cm}^{-1}$, involving the Fe-N(pyz) stretching.

The $E$ vibration at $85 \mathrm{~cm}^{-1}$ is shown in ESI. The A, B and E vibrations involving the collective libration of pyrazine with significant amplitude of irons are predicted at 66 and $67 \mathrm{~cm}^{-1}$

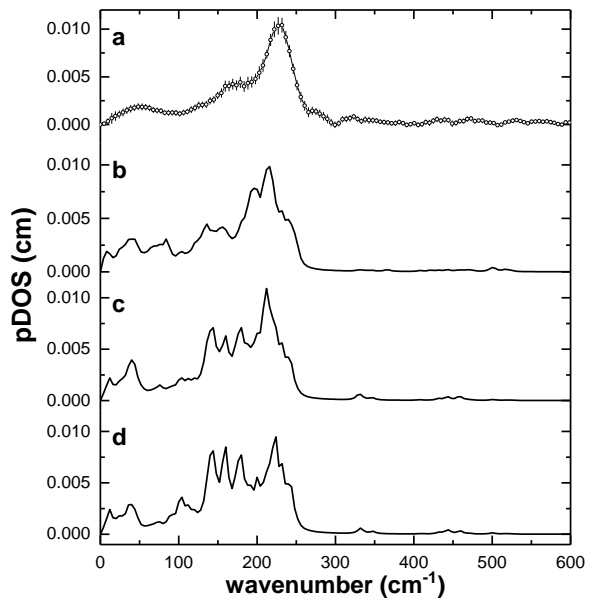

Figure 5. Comparison of the experimental and DFT calculated (CAMB3LYP/CEP-31g) pDOS for the HS state of 1. a Experimentally obtained pDOS of $\mathbf{1}$ taken at $T=305 \mathrm{~K}$. pDOS calculated $\mathbf{b}$ for vibrations involving all iron atoms, $\mathbf{c}$ for three irons lying on the $\mathrm{S}_{4}$ axis and $\mathbf{d}$ for the central $\mathrm{Fe}(1)$ are shown.

It is worthy to note that in the 3D polymeric lattice of $\mathbf{1}$ all vibrations, including the low-energy phonons are determined by the atomic forces due to covalent bonds. Hence, the vibrations calculated for the model systems also include crystal modes. In other words, on a contrary to calculations of a system of lower dimensionality we do not omit the low-energy vibrations depending on the intermolecular interactions and obtain at least a fair approximation of the character of low-energy modes.

\section{DFT calculated normal modes in comparison to Raman and IR} spectroscopy.

A detailed Raman and IR study on the series of $[\mathrm{Fe}($ pyrazine $)]\left[\mathrm{M}(\mathrm{CN})_{4}\right] \cdot 2 \mathrm{H}_{2} \mathrm{O}(\mathrm{M}=\mathrm{Ni}, \mathrm{Pd}, \mathrm{Pt})$ complexes has been published by Molnár at al...23 The fair similarity of the pDOS of 1 and 2 motivates a comparison of the normal mode results performed for our model with the data given in ref 23. A detailed discussion is given in the Supplementary Information. Summarizing, our DFT calculations confirm by and large the assignment given in ref. 24 . The output Gaussian frequency files are available from authors at request. 


\section{Estimation of intramolecular cooperativity}

In order to quantify enthalpic intramolecular cooperativity in symmetrical trinuclear iron SCO complexes we have introduced the energy parameter $\mathrm{H}_{\text {coop }}$ which has been defined as the difference of the LS to HS transition energy for a center with two LS and two HS nearest neighbours, respectively. ${ }^{12}$ For trinuclear SCO complexes $\mathrm{H}_{\text {coop }}$ can be calculated by DFT calculations in the following way: (i) Calculation of the energies of a HS-LS-HS and a HS-HS-HS state, the difference of the energies than leads to $\triangle E(H S)$. (ii) Calculation of the energies of a LS-LS-LS and a LS-HS-LS state leads to $\Delta E(L S)$. (iii) the intramolecular cooperativity parameter is than given according to $\mathrm{H}_{\text {coop }}=\Delta \mathrm{E}(\mathrm{LS})-\Delta \mathrm{E}(\mathrm{HS})$. It should be noted that the intramolecular cooperativity corresponds to the short range interactions in the classical model of Spiering. ${ }^{24}$ For SCO compounds in which the Fe(II) centres are bridged with flexible ditetrazole ligands, i.e. for systems exhibiting a soft spin transition $\mathrm{H}_{\text {coop }}$ is about zero, while for complexes of rigid amino-triazole, typically revealing sharp transition values of $\mathrm{H}_{\text {coop }}$ of $20-30 \mathrm{kJmol}^{-1}$ are obtained. ${ }^{12}$ This relatively high value is a consequence of geometric distortion extorted by the neighbours of different spin that follows the rule "higher spin of the neighbours induces longer Fe-N bond lengths". This distortion causes also a corresponding shift of the Fe-N stretching vibrations influencing the vibrational energy. The latter effect was later experimentally shown by comparing the pDOS of the LS phase and LS $\mathrm{Fe}(\mathrm{II})$ in a Zn(II) matrix for two different 1D SCO systems based on triazole derivatives. ${ }^{16 a, c}$

The concept described above can be applied to larger SCO units as well which motivates the determination of $\mathrm{H}_{\text {coop }}$ for the model molecule of 1 displayed in Figure 3 . In order to do so we optimised the geometries and determined the energies of the four following systems:

a) All Fe atoms in the LS state, with the energy $E(L S)$.

b) LS matrix (all Fe atoms except the central $\mathrm{Fe}(1)$ are in the LS state) with $\mathrm{Fe}(1)$ in the HS state, denoted as $1 \mathrm{HS}$ _LS with the energy E(1HS_LS);

c) A Zn(II) matrix as a model for a HS matrix with $\mathrm{Fe}(1)$ in the LS state, denoted as 1LS_Zn with the energy E(1LS_Zn);

d) A Zn(II) matrix as a model for a HS matrix with $\mathrm{Fe}(1)$ in the HS state, denoted as 1HS_Zn with the energy E(1HS_Zn).

The former three geometries were optimised within the $S_{4}$ symmetry, the latter for the $C_{1}$ one. The parameter $H_{\text {coop }}$ was then derived as [E(1HS_LS)-E(LS)] - [E(1LS_Zn)-E(1HS_Zn), i.e. as a difference between the LS to HS transition electronic energies in a low-spin and in a $\mathrm{Zn}$ (II) matrix, the latter being the structural model of the high-spin matrix. This approach is schematically shown in Scheme 1 . The results of the calculations together with the selected metal ligand bond lengths are shown in Table 3.

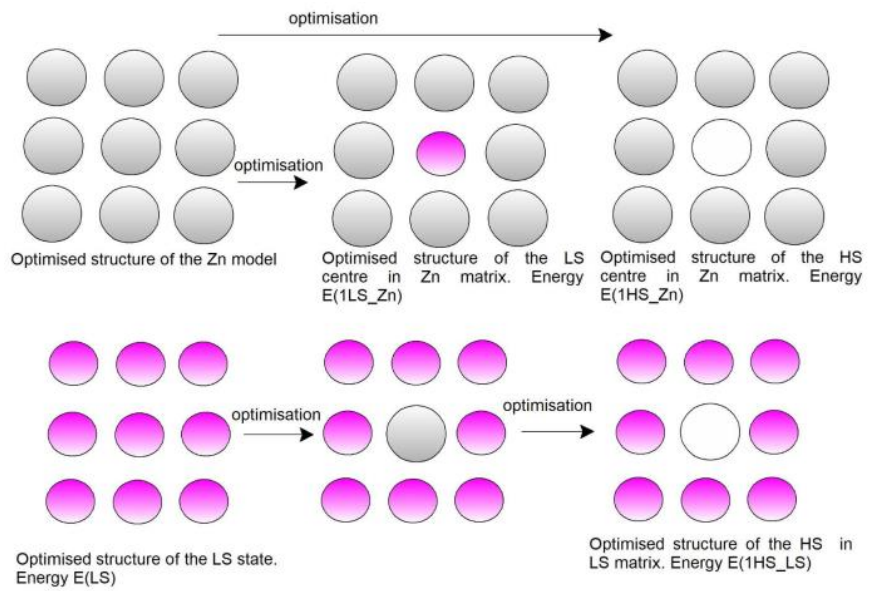

$H_{\text {coop }}=\left[E\left(1 H S \_L S\right)-E(L S)\right]-\left[E\left(1 H S \_Z n\right)-E\left(1 L S \_Z n\right)\right]$

LS Fe

$\mathrm{HS} \mathrm{Fe}$

$\mathrm{Zn}$

Scheme 1. Schematic representation of the computational approach to derive the cooperativity parameter $\mathrm{H}_{\text {coop }}$ for the model of 1 . Only a $3 \times 3$ grid is shown for clarity. The circle in the centre of the $3 \times 3$ grid represent that in the inversion centre of the cuboid of model molecule. Note that to obtain the structure with $\mathrm{HS} \mathrm{Fe}(1)$ in the LS matrix (1HS_LS) the preceding optimisation of the structure with $\mathrm{Zn}$ in the inversion centre in the LS matrix was necessary in order to localise the centre with longer Fe-N bond lengths.

Table 3. Calculated electronic energy differences and principal metal-ligand bonds lengths for the model of LS and HS-Fe(1) in LS-Fe(II) and Zn(II) matrices.

\begin{tabular}{|c|c|c|c|}
\hline DFT functional & CAM-B3LYP & B3LYP* & B3LYP \\
\hline$\Delta \mathrm{E}\left(\mathrm{LS} \_\right.$matrix $)\left(\mathrm{kJmol}^{-1}\right)$ & 9 & 41 & 15 \\
\hline$\Delta \mathrm{E}(\mathrm{Zn}-\mathrm{matrix})\left(\mathrm{kJmol}^{-1}\right)$ & -6 & 26 & 1 \\
\hline $\mathrm{H}_{\text {coop }}\left(\mathrm{kJmol}^{-1}\right)$ & 15 & 15 & 14 \\
\hline \multicolumn{4}{|c|}{ LS } \\
\hline \multicolumn{4}{|c|}{ Distances (low-spin state, LS) (Å) } \\
\hline $\mathrm{Fe}(1)-\mathrm{N}(\mathrm{C})$ & 1.956 & & \\
\hline $\mathrm{Fe}(1)-\mathrm{N}(\mathrm{pyz})$ & 2.013 & & \\
\hline $\mathrm{Pd}-\mathrm{C}^{\mathrm{a}}$ & 2.012 & & \\
\hline $\mathrm{Fe}(2)-\mathrm{N}(\mathrm{pyz})_{\mathrm{Fe}(1)}$ & 2.013 & & \\
\hline $\mathrm{Fe}(2)-\mathrm{N}(\mathrm{pyz})_{\text {out }}$ & 2.013 & & \\
\hline \multicolumn{4}{|c|}{ Distances (LS-Fe(1) in Zn_matrix, 1LS_Zn) (Å) } \\
\hline $\mathrm{Fe}(1)-\mathrm{N}(\mathrm{C})$ & 1.974 & & \\
\hline $\mathrm{Fe}(1)-\mathrm{N}(\mathrm{py})$ & 2.011 & & \\
\hline $\mathrm{Pd}-\mathrm{C}^{\mathrm{a}}$ & 2.030 & & \\
\hline $\mathrm{Zn}(2)-\mathrm{N}(\mathrm{pyz})_{\mathrm{Fe}(1)}$ & 2.191 & & \\
\hline $\mathrm{Zn}(2)-\mathrm{N}(\mathrm{pyz})_{\text {out }}$ & 2.153 & & \\
\hline \multicolumn{4}{|c|}{$\mathrm{HS}$} \\
\hline \multicolumn{4}{|c|}{ Distances (HS-Fe(1) in Zn_matrix, 1HS_Zn) (Å) } \\
\hline $\mathrm{Fe}-\mathrm{N}(\mathrm{C})$ & $2.142,2.141$ & & \\
\hline Fe-N(py) & 2.192. 2.212 & & \\
\hline $\mathrm{Pd}-\mathrm{C}^{\mathrm{a}}$ & 2.018 & & \\
\hline $\mathrm{Zn}(2)-\mathrm{N}(\mathrm{pyz}) \mathrm{Fe}(1)$ & $2.197,2.192$ & & \\
\hline $\mathrm{Zn}(2)-\mathrm{N}(\mathrm{pyz})_{\text {out }}$ & $2.145,2.144$ & & \\
\hline \multicolumn{4}{|c|}{ Distances (HS-Fe(1) in LS_matrix, 1HS_LS ) (Å) } \\
\hline $\mathrm{Fe}-\mathrm{N}(\mathrm{C})$ & 2.106 & & \\
\hline Fe-N(py) & 2.1865, & & \\
\hline $\mathrm{Pd}-\mathrm{C}^{\mathrm{a}}$ & 2.000 & & \\
\hline $\mathrm{Fe}(2)-\mathrm{N}(\mathrm{pyz})_{\mathrm{Fe}(1)}$ & 2.011 & & \\
\hline $\mathrm{Fe}(2)-\mathrm{N}(\mathrm{pyz})_{\text {out }}$ & 2.010 & & \\
\hline
\end{tabular}


The $\mathrm{H}_{\text {coop }}$ value of $15 \mathrm{kJmol}^{-1}$ for $\mathbf{1}$ indicates significant intramolecular cooperativity. Similarly to the previously reported values for the pentanuclear models of a 1D 4-amino-1,2,4-triazole complex ${ }^{12}$ it is not dependent on the chosen functional. However, its magnitude is smaller than those derived for the 1D system, where $\mathrm{H}_{\text {coop }}$ lies in between 24 and $34 \mathrm{kJmol}^{-1}$. The analysis of the calculated bond lengths of $\mathrm{Fe}(1)-\mathrm{N}$ reveals the following picture: While for the 1D Fe(atrz $)_{3} \mathrm{Cl}_{2}$ model the presence of the neighbours of different spin resulted in a change of all Fe-N bonds (namely the elongation of the LS bonds of about 0.02-0.024 $\AA$ and shortening of the HS bonds of about 0.030-0.036 $\AA$ ), for 1 a different pattern is observed. The Fe$\mathrm{N}(\mathrm{C})$ bonds for the LS state of $\mathrm{Fe}(1)$ undergo elongation of $0.018 \AA$ when the LS matrix is replaced by a HS-matrix which is modelled in this study by a $\mathrm{Zn}$ (II) matrix. Yet the Fe-N(pyz) bonds are nearly the same for both the LS (2.013 $\AA$ ) and the Zn $(2.011 \AA)$ matrix. On the other hand, for the HS Fe(1) the Fe-N(pyz) bonds in a LS matrix are on average less than $0.016 \AA$ shorter than those in the $\mathrm{Zn}$ one, yet the corresponding shortening of the $\mathrm{Fe}-\mathrm{N}(\mathrm{C})$ bonds is more than twice as large (0.0355 ̊).

Hence, while in the previously studied 1D system ${ }^{12}$ the distort ion due to presence of the neighbours of different spin was threedimensional (i.e. involved all six bonds in the octahedral coordination core) for the 3D system under study the distortion is essentially limited to the plane of the cyanide ligands. Noteworthy, these are also the Pd-CN bonds which are distorted. The HS Fe(1) in the LS matrix shows a shortening of the neighbouring Pd-C distances of $0.012 \AA$ compared to the full LS state of 1, while the corresponding distance in the $\mathrm{Zn}$ (II) matrix with the LS Fe(1) defect is elongated by $0.012 \AA$ A compared to the $\mathrm{Zn}$ (II) matrix.

Furthermore, it is interesting to compare the effective change of the metal-ligand bond lengths of $\mathrm{Fe}(1)$ and its neighbours. If we sum up all bond lengths given in Table 3, taking into account that $\mathrm{Fe}(1)$ has two $\mathrm{Fe} / \mathrm{Zn}$ and four $\mathrm{Pd}$ neighbours, we obtain a net elongation of $0.994 \AA$ for the HS->LS switching in the Zn matrix and $0.889 \AA$ A for the one in the LS-matrix. Thus the effective increase of net metal-ligand bond lengths of ca. $0.1 \AA$ is induced by the matrix with longer bond lengths. Interestingly, if compared with data for the pentanuclear model of 1D Fe(atrz) ${ }_{3} \mathrm{Cl}_{2}$ (cf. ref. 12, Table 4, see data for B3LYP* calculations), the corresponding difference of net bond lengths elongation for the switching Fe(II) and its two neighbours is only $0.018 \AA$ and is slightly larger than for the low-spin neighbours. This finding may imply that the vibrational entropy pattern may look different for the 1D and 3D systems. For the model of Fe(atrz) ${ }_{3} \mathrm{Cl}_{2}$ (ref. 12) the vibrational entropy contribution of the LS to HS transition was considerably higher for the transition at the presence of low-spin neighbours (ca. 30-35 e.u. at $200 \mathrm{~K}$ and ca. 40 e.u. at $400 \mathrm{~K})$. In order to estimate the cooperative entropic effects for the 3D system under study the vibrational entropy contribution was calculated on the basis of the obtained pDOS (Figure 6).

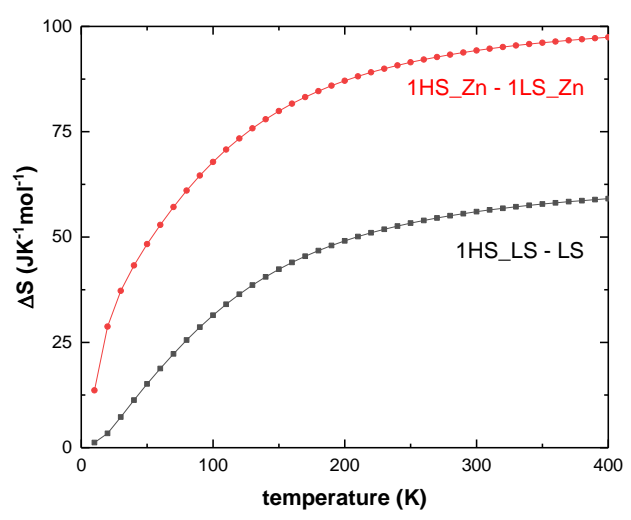

Figure 6. Temperature dependence of the calculated (CAM-B3LYP/CEP-31G) vibrational entropy change for the LS(LS matrix) -> HS(LS matrix) (in black) and LS(Zn_matrix) -> HS(Zn_matrix) (in red) in 1.

In fact, the results are opposite to those derived for the 1D system $\mathrm{Fe}(\mathrm{atrz})_{3} \mathrm{Cl}_{2}$. The spin transition vibrational entropy for the transition in the $\mathrm{Zn}$ matrix is higher than that in the LS Fe matrix. Therefore, the following picture arises: In the mentioned 1D system the LS state is stabilized energetically and destabilized entropically since in the presence of LS neighbours $\Delta \mathrm{S}_{\mathrm{vib}}$ is higher compared to the HS neighbour environment. On the contrary in the 3D system under study the entropic effect stabilizes the LS centre in a LS environment since $\Delta \mathrm{S}_{\text {vib }}$ is lower than in a $\mathrm{Zn}$ ( or HS) matrix. On the other hand, the corresponding energetic stabilization (given by $\mathrm{H}_{\text {coop }}$ ) is two third to half of what was derived for the 1D system. In our opinion this difference to the 1D systems is due to a different pattern of the distortions of the LS and HS centres by the matrix of other spins. In Figures 7 and 8 the calculated pDOS of LS and HS Fe(1) is shown in a LS and a Zn(II) matrix, the latter being a model for a HS matrix.

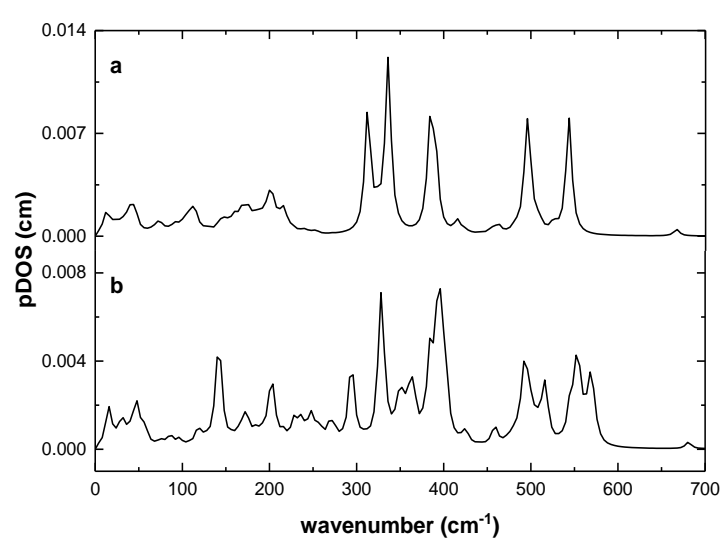

Figure 7. Calculated pDOS for LS Fe(1) $\mathbf{a}$ in a $\mathrm{LS}$ and $\mathbf{b}$ in a $\mathrm{Zn}(\mathrm{II})$ matrix 


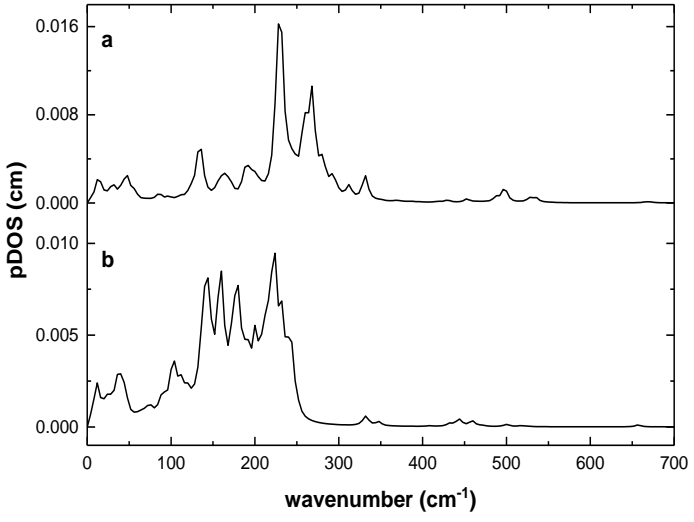

Figure 8. Calculated pDOS for $\mathrm{HS} \mathrm{Fe(1)} \mathrm{a} \mathrm{in} \mathrm{a} \mathrm{LS} \mathrm{and} \mathbf{b}$ in a $\mathrm{Zn}(\mathrm{II})$ matrix.

In the analogous pDOS derived for the $1 \mathrm{D}$ system ${ }^{16 \mathrm{c}}$ one observes that the respective change in the calculated pDOS for Fe(II) is very significant for the LS centre. On the other hand, the change for the HS one is fairly limited. In the case of $\mathbf{1}$ the pattern is different. While the differences for the LS centre are visible but qualitatively small and concern mainly the high-energy Fe-N(C) vibrations, the shift for the HS centre towards higher frequencies is significant, leading to the observed increased entropy of the LS to HS transition for the LS "defect" in a HS (Zn(II)) matrix.

\section{Experimental}

The complexes were synthesised according to the procedure by Real et al. ${ }^{3}$ starting from the $97 \%$ enriched ${ }^{57} \mathrm{Fe}\left(\mathrm{BF}_{4}\right)_{2} \cdot 6 \mathrm{H}_{2} \mathrm{O}$ as microcrystalline material (see SI). The DFT calculations were performed using Gaussian 09 package. ${ }^{25}$ The structures were optimised and the vibrations were calculated using the CAM-B3LYP functional ${ }^{26}$ and the CEP-31g basis set ${ }^{27}$ and the model molecules described above. The vibrations for the $\mathrm{HS} \mathrm{Fe}$ (II) in $\mathrm{Zn}$ (II) matrix were assigned on the basis of the vibrations calculated for the purely Zn(II) system. The vibrational contribution to entropy was computed as reported previously. ${ }^{28}$ The electronic energies for the different spin isomers in two different matrices were also calculated using the $B 3 L Y{ }^{* 29}$ and B3LYP30 functionals with the same basis set for the geometries obtained with CAM-B3LYP. The stability check and reoptimisation of the wave function was performed in each case. NIS measurements for 1 were performed at the PETRA III beamline P01 at DESY in Hamburg, Germany and for $\mathbf{2}$ at the Nuclear Resonance Beamline ID $18^{31}$ of the European Synchrotron Radiation Facility (ESRF) in Grenoble, France. The $6 \mathrm{GeV}$ electron storage ring at ESRF was operated in 16 bunch mode and for our experiment the incident beam was monochromatized down to $0.83 \mathrm{meV}\left(\sim 6.7 \mathrm{~cm}^{-1}\right)$. The $6 \mathrm{GeV}$ electron storage ring at DESY was operated in 40 bunch mode and for our experiment the incident beam was monochromatized down to $\sim 1 \mathrm{meV}\left(\sim 8 \mathrm{~cm}^{-1}\right)$.

\section{Conclusions}

The pDOS of dehydrated and hydrated isomers of [Fe(pyrazine)] $\left[\mathrm{Pt}(\mathrm{CN})_{4}\right]$ in their $\mathrm{HS}$ and LS states have been measured experimentally via NIS and simulated by means of DFT calculations. The dehydrated complex was modelled with DFT calculations using a $\left\{\left[\mathrm{Fe}_{15} \text { (pyrazine }\right)_{20}\right]\left[\mathrm{Pd}(\mathrm{CN})_{4}\right]_{12}$ $\left.\left(\mathrm{CH}_{3} \mathrm{CN}\right)_{24}\right\}^{6+}$ model molecule for the LS state and a $\left.\left\{\left[\mathrm{Zn}_{15} \text { (pyrazine) }\right)_{20}\right]\left[\mathrm{Pd}(\mathrm{CN})_{4}\right]_{12}\left(\mathrm{CH}_{3} \mathrm{CN}\right)_{24}\right\}^{6+}$ structural model of the $\mathrm{HS}$ isomer. This procedure allowed the attribution of the observed bands in the pDOS to vibrational modes of the SCO material. The calculations for the corresponding systems with the HS Fe(II) in a LS Fe(II) matrix and LS and HS Fe(II) centres in a Zn(II) matrix, allowed the estimation of the intramolecular cooperativity in the system under study. Two dimensional distortion of LS Fe(II) extorted by the $\mathrm{Zn}$ (II) matrix was found involving only the Fe-N(CN) bonds. The HS Fe(II) centre in the LS $\mathrm{Fe}(\mathrm{II})$ matrix is also distorted in the plane of $\left[\mathrm{M}(\mathrm{CN})_{4}\right]^{2-}$ entities, yet some additional smaller axial distortion occurs along the $\mathrm{Fe}-$ pyz-Fe axis. This distortional pattern is different in the 1D Fe(II) SCO chains based on the bridging triazole derivative ligand, where a three dimensional distortion of the Fe(II) occurs when the neighbours are in different spin states. This different behaviour results in a lower intramolecular enthalpic cooperativity and entropic factors increasing the cooperativity.

\section{Conflicts of interest}

There are no conflicts to declare.

\section{Acknowledgements}

This work has been supported by the German Research Foundation (DFG) within the SFB/TRR 173 "SPIN+X" and by the German Ministry of Research (BMBF) under 05K16UKA. Volker Schünemann and Juliusz $A$. Wolny are indebted to Allianz für Hochleistungsrechnen Rheinland-Pfalz (AHRP) for providing CPU-time within the project TUKL-NANOSCODFT. 


\section{Notes and references}

${ }^{1}$ C. M. Muñoz and J.-A. Real, in Spin-Crossover Materials, M.A. Halcrow, Editor, Wiley, 2013 and references therein.

2 Y. Garcia, V. Niel, Muñoz and J.-A. Real,

Top. Curr. Chem., 2004, 233, 229 and ref. therein;

3 V. Niel, J.M. Martrinez-Agudo,C. M. Muñoz, A.B. Gaspar and J.-A. Real, Inorg. Chem. 2001, 40, 3838.

4 a) S. Bonhommeau, G. Molnár, A. Galet, A. Zwick, J.-A.Real, J.J. MacGarvey, A. Bousseksou, Angew. Chem. Int. Ed., 2005, 44, 4069; b) S. Cobo, D. Ostrovskii, S. Bonhommeau, L. Vendier, G. Molnár, L. Salmon, K. Tanaka, A. Bousseksou, J. Am. Chem. Soc., 2008, 130, 9019; c), S. Bonhommeau , G. Molnár, S. Cobo, D. Ostrovskii, Polyhedron, 2009, 28, 1610.

${ }^{5}$ E. Collet, L. Henry, L. Piñeiro-López, L. Toupet, J.-A. Real, Curr. Inorg. Chem., 2016, 6, 61.

${ }^{6}$ R.Bertoni, M. Lorenc, H. Cailleau, A. Tissot, J. Laisney, M.-L. Boillot, L. Stoleriu, Al. Stancu, C. Enanchescu and E. Collet., Nature Materials, 2016, 15, 606

7 H. Peng, S. Tricard, G. Félix, G. Molnár, W. Nicolazzi, L. Salmon and A. Bousseksou, Angew. Chem. Int. Ed. 2014, 53, 10894.

8 G. Félix, M. Mikolasek, H. Peng, W. Nicolazzi, G. Molnár, A. I. Chumakov, L. Salmon, A. Bousseksou, Phys. Rev. B, 2015, 91, 024422 ${ }_{9}$ M. Mikolasek, K. Ridier, D. Bessas, V. Cenrantola, G. Félix, G. Chaboussnat, M. Piedrahita-Bello, E. Angulo-Cervera, L. Godard, W. Nicolazzi, L. Salmon, G. Molnár, A. Bousseksou J. Phys. Chem. Lett. 2019, 10, 1511.

10 a) G. Félix, W. Nicolazzi, L. Salmon, G. Molnár, M. Perrier, G. Maurin, J. Larionova, J. Long, Y. Guari, A. Bousseksou, Phys. Rev. Lett., 2013, 110, 23501; b) G. Félix, M. Mikolasek, G. Molnár, W. Nicolazzi, A. Bousseksou, Eur. J. Inorg. Chem.2018, 435. c) M. Mikolasek, G. Félix, W. Nicolazzi, G. Molnár, L. Salmon, A. Bousseksou, New. J. Chem. 2014, 38, 1834.

11 J. A. Wolny, V. Schünemann, Z. Németh, and G. Vankó, C. R. Chimie 2018, 21, 1152, and references therein.

12 S. Rackwitz, W. Klopper, V. Schünemann, J.A. Wolny, Phys. Chem. Chem. Phys, 2013, 15, 15450.

${ }^{13}$ T. Tayagaki, A. Galet, G. Molnár, M. Carmen Muñoz, A. Zwick, K. Tanaka, J.-A. Real, A. Bousseksou, J. Phys. Chem. B 2005, 109, 14859. 14 J. A. Rodriguez-Velamazán, M. A. González, J.-A- Real, M. Castro, M. Carmen Muñoz, A.B. Gaspar, R. Ohtani, M. Ohba, K. Yoneda, Y. Hijikata, N. Yanai, M. Mizuno, H. Ando, S. Kitagawa, J.Am. Chem. Soc., 2012, 134, 5083.

${ }^{15}$ E. Collet, G. Azzolina, T. Ichii, L. Guerin, R. Bertoni, A. Moréac, M. Cammarata, N. Daro, G. Chastanet, J. Kubicki, K. Tanaka, S. F. Matar, Eur. Phys. J. B 20199212.

${ }^{16}$ a) K. Jenni, L. Scherthan, I. Faus, J. Marx, C. Strohm, M. Herlitschke, H.-C. Wille, P. Würtz, V. Schünemann, J.A. Wolny Phys. Chem. Chem. Phys. 2017, 19, 18880 b) J.A. Wolny, S. Sakshath, K. Jenni, L. Scherthan, H. Auerbach, H.-C. Wille, A.-M. Li, C. von Malotki, E. Rentschler and V. Schünemann

Hyperfine Interact. 2018 239, 22 c) J. A. Wolny, I. Faus, J. Marx, R. Rüffer, A. Chumakov, K. Schlage, H.-C. Wille, and V. Schünemann, Magnetochemistry 2016, 2, 19 d) S. Rackwitz, J. A. Wolny, K. Muffler,
K. Achterhold, R. Rüffer, Y. Garcia, R. Diller, V. Schünemann Phys. Chem.Chem. Phys. 2012, 14, 14650.

17 a) P. Gütlich, H.A. Goodwin, Top. Curr. Chem., 2004, 233 , 1 ; P. Gütlich, Y. Garcia, H.A. Goodwin, Chem. Soc. Rev., 2000, 29, 419427; c) A. Hauser, J. Jeftić, H. Romstedt, R. Hinek, H. Spiering, Coord. Chem. Rev., 1999, 190-192, 471; d) M. Sorai, J. Ensling, P. Gütlich, Chem. Phys., 1976, 18, 199; e) J. Jung, G. Schmitt, A. Hauser, L. Wiehl, K. Knorr, P. Gütlich, Z. Phys. B, 1996, 100, 523.

${ }^{18}$ C. Baldé, C., Desplanches, J. F. Létard , G., Chastanet, Polyhedron 2017, 123, 138 and references therein.

${ }_{19}$ M. S. Sylla, C. Baldé, N. Daro, G. Chastanet., J. Soc. Ouest-Afr. Chim. 2017, 043, 37;

$20 \mathrm{~J}$. Rodriguez-Hernandez, A.A. Lemus-Santana, J. Ortiz-Lopez, S. Jimenez-Sandoval, E. Reguera, J. Solid State Chem., 2010, 183, 105. ${ }^{21}$ M. Ohba, K. Yoneda, G. Agust, M. Carmen Muñoz, A. B. Gaspar, J.A. Real, M. Yamasaki, H. Ando, Y. Nakao, S. Sakaki, S. Kitagawa, Angew. Chem. Int. Ed. 2009, 48, 4767.

22 H. Ando, Y. Nakao, H. Sato, M. Ohba, S. Kitagawa, S. Sakaki, Chem. Phys. Lett., 2011, 511, 399.

${ }^{23}$ G. Molnár. V. Niel, A. B. Gaspar, J.-A. Real, A. Zwick, A. Bousseksou, J.J. McGarvey, J.Phys.Chem. B, 2002, 106, 9701.

${ }^{24}$ H. Spiering, Top. Curr. Chem., 2004, 235, 171.

${ }^{25}$ M. J. Frisch, G. W. Trucks, H. B. Schlegel, G. E. Scuseria, M. A. Robb, J. R. Cheeseman, G. Scalmani, V. Barone, B. Mennucci, G. A. Petersson, H. Nakatsuji, M. Caricato, X. Li, H. P. Hratchian, A. F. Izmaylov, J. Bloino, G. Zheng, 'J. L. Sonnenberg, M. Hada, M. Ehara, K. Toyota, R. Fukuda, J. Hasegawa, M. Ishida, T. Nakajima, Y. Honda, O. Kitao, H. Nakai, T. Vreven, J. A. Montgomery, Jr., J. E. Peralta, F. Ogliaro, M. Bearpark, J. J. Heyd, E. Brothers, K. N. Kudin,

V. N. Staroverov, T. Keith, R. Kobayashi, J. Normand, K. Raghavachari, A. Rendell, J. C. Burant, S. S. lyengar, J. Tomasi, M. Cossi, N. Rega, J. M. Millam, M. Klene, J. E. Knox, J. B. Cross, V. Bakken, C. Adamo, J. Jaramillo, R. Gomperts, R. E. Stratmann, O. Yazyev, A. J. Austin, R. Cammi, C. Pomelli, J. W. Ochterski, R. L. Martin, K. Morokuma, V. G. Zakrzewski, G. A. Voth, P. Salvador,

J. J. Dannenberg, S. Dapprich, A. D. Daniels, O. Farkas,

J. B. Foresman, J. V. Ortiz, J. Cioslowski and D. J. Fox,

Gaussian 09, Revision D.01, Gaussian, Inc., Wallingford CT,2013.

${ }^{26}$ T. Yanai; D. P.; Tew, N. C., Handy, Chem. Phys. Lett. 2004, 393, $51-$ 57.

${ }^{27}$ a) W.J. Stevens, H. Basch, J. Krauss, J. Phys. Chem., 1984, 81, 6026. b) W.J. Stevens, M. Krauss, H. Basch, P.G. Jasien, Can. J. Chem. 1992, 70, 612. c) T.R. Cundari, W.J. Stevens, J. Chem. Phys, 1993, 98, 5555. ${ }_{28}$ R. Benda, A. Bousseksou, A. I. Chumakov, A. Dennis, C. Hert, P. Gütlich, A. Höfer, J. J. McGarvey, H. Paulsen K. L. Ronayne, V. Schünemann, H. Spiering, A. X. Trautwein, H. Winkler J. A. Wolny, Phys. Chem. Chem. Phys., 2006, 8, 4685

${ }^{29}$ M. Reiher, O.Salomon, B.A. Hess, Theor. Chim. Act., 2001, 107, 49. b) O. Salomon, M. Reiher, B.A. Hess, J. Chem. Phys., 2002, 117, 4729 ${ }^{30}$ A.D. Becke, J. Chem. Phys.,1993, 98, 5648.

${ }^{31}$ R.Rüffer and A.I.Chumakov, Hyperfine Interaction, 1996, 97/98 589. 